\title{
ALGUNAS CONSIDERACIONES SOBRE LAS CORTESANAS EN LA COMEDIA DE PLAUTO
}

\section{Carlos Felipe Amunátegui}

Este artículo trata de la condición social y jurídica de las cortesanas en Roma durante el siglo II a.C. Para analizar dicha situación, el autor utiliza las comedias de Plauto a fin de explorar las particularidades de su mundo. Intenta determinar la tipología de cortesanas que se encuentra en la comedia de Plauto, como también las diferencias que existen entre ellas. Especial tratamiento reciben la prohibición jurídica de contraer matrimonio que pueda pesar sobre ellas y el concubinato.

Carlos Felipe Amunátegui Perelló. Doctorado en Derecho Patrimonial en la Universidad Pompeu Fabra de Barcelona. Profesor Derecho Romano, Universidad Católica de Chile. Miembro de la Schola Serviana Iuris Civilis. 
Al menos que se permita a los que lamentarán siempre no haber conocido a la juventud embriagada de la tierra, que llamamos vida antigua, que se les permita revivir, a través de la ilusión fecunda, el tiempo en que la desnudez humana podía revelarse bajo los contornos de una cortesana sagrada, ante los veinte mil peregrinos que cubrieron las playas de Eleusis; en que el amor más sensual, el divino amor del que hemos nacido, era sin mancha, sin vergüenza, sin pecado; que se les permita olvidar dieciocho siglos bárbaros, hipócritas y feos, elevarse de la charca al manantial, regresar piadosamente a la belleza original, reconstruir el Gran Templo al son de flautas encantadas y consagrar con entusiasmo en los santuarios de la verdadera fe sus corazones siempre arrebatados por la inmortal Afrodita.

(Pierre Louis, Afrodita.)

\section{Introducción}

$\mathrm{E}$

universal respeto por Plauto se debe a que es uno de los comediógrafos que más sólidamente nos ha hecho reír en los últimos 2.200 años. Como tantos literatos de la Antigüedad, su historia personal es incierta para nosotros, aunque su legado literario está tan vivo y presente hoy como ayer.

Su obra se enmarca dentro de la comedia palliatina, género dramático de gran popularidad durante el siglo II a.C. Como sus contemporáneos, centró su actividad más que en la creación de piezas nuevas, en la adaptación a la lengua latina de la nueva comedia ática del siglo IV a.C, especialmente las de Menandro, Filemón y Dífilo. Así, puso en escena diferentes obras tomadas de originales griegos cuyos textos debieron ser adaptados a las necesidades romanas.

Diferentes razones impulsaron a los dramaturgos romanos en esa dirección; por un lado, la comedia nacional latina, la atelana, se encontraba aún en estado embrionario, mientras que la creciente influencia helenizante que invadía a Roma a contar de las Guerras Púnicas ofrecía una variante dramática mucho más desarrollada y perfecta que los rudos inicios cómicos italianos.

Otro factor importante se observa en la situación política y moral que imperaba en Roma con posterioridad a las Guerras Púnicas. El pueblo victorioso que se imponía como la única potencia relevante en el Mediterráneo no aceptaba con liviandad las críticas a sus costumbres e instituciones que caracterizaba a la comedia. Tristemente conocido es el caso del poeta Nevio, 
que fue encarcelado en un proceso que esgrimió en su contra la poderosa familia de los Metellos al ser ridiculizados en una de sus obras ${ }^{1}$.

De esta manera, garantizaba mejores resultados y era políticamente más seguro para los comediantes romanos centrar sus esfuerzos en la traducción y adaptación de modelos originalmente griegos para sus obras. La acción se desenvolvía en la Hélade, los personajes usaban nombres griegos y se vestían como tales, llegando Plauto incluso a referirse a las costumbres y leyes romanas como "bárbaras".

Sin embargo, la labor de los cómicos palliatinos no se limitó a la mera traducción de los originales griegos. Como resulta natural, no puede esperarse que dos sociedades diferentes, separadas por el espacio, la historia, la lengua y dos siglos de distancia puedan comprenderse recíprocamente sin algún proceso de modificación en la estructura misma de la obra para que conserve efectos cómicos equiparables. El romano, aún rudo, provinciano y campesino, no podría haber comprendido sin más las sutilezas de la refinada, mercantil y urbana Atenas del siglo IV a.C. Los gustos y costumbres de ambas sociedades eran diferentes e incluso opuestos, por lo que la simple traducción de la obra resultaría incongruente para el romano. De esta manera, Plauto y, en menor medida Terencio, se vieron forzados a efectuar cambios, en ocasiones sustanciales, a las obras representadas. Centrándonos en el primero, entre los mayores cambios realizados respecto a la nueva comedia ática se cuentan la música y cantos, las exageraciones, las identificaciones formuladas con acertijos, la personificación de objetos materiales, la mezcla y supresión de elementos pertenecientes a dos o más comedias, la introducción de mímica y gestos obscenos, la prolongación de determinados papeles y la romanización de las comedias.

Es el último elemento el que mayor lugar a debate proporciona en lo referente al derecho romano, puesto que las opiniones varían desde aquella que sostiene que la comedia plautina es completamente romana, tanto en su ambiente como en el derecho que refleja ${ }^{2}$, hasta aquella que sostiene su carácter absolutamente griego.

La verdad es que dichas posiciones extremas suelen no tomar en cuenta el ambiente en que las comedias se desarrollan, como tampoco los elementos dramáticos y su finalidad; se llegó incluso a confeccionar listas cerradas de asuntos jurídicos tratados en Plauto ${ }^{3}$, siempre con el error de no

${ }^{1}$ Al respecto, véase Guarino, Antonio: "Minima de Mulieribus”, 1993, Vol. II, pp. 349 y ss.

${ }^{2}$ Dicha posición ha tenido profunda influencia en la doctrina italiana a partir de su planteamiento por Costa, Emilio: Il Diritto Privato nelle Commedie di Plauto.

${ }^{3}$ Véase al respecto el meticuloso trabajo de Bekker, Ernst Inmanuel, en su ya clásico Die römischer Komier als Rechtszeugen, pp. 53 y ss. 
distinguir el efecto buscado por el autor y la posibilidad de adaptación que ofrece la escena, llegando a evidentes contradicciones no sólo con aquello que conocemos del derecho romano de la época, sino entre diferentes fragmentos de las distintas obras. Esta visión ha sido superada con el tiempo y el uso del material plautino se hizo sólo fragmentario para apoyar tal o cual tesis sin analizar en profundidad los textos citados. La cuestión permaneció igual hasta que Watson volvió a utilizar la comedia plautina a fin de desarrollar un sistema jurídico para la época con un método diferente al empleado hasta entonces, analizando caso a caso la posible procedencia de los fragmentos, como también su posición en la obra y la romanización más o menos profunda a que puedan estar sometidos ${ }^{4}$.

Para el auditorio romano, representar una comedia con elementos exclusivamente helénicos habría supuesto un esfuerzo desmesurado que rebasaría completamente sus capacidades. Las costumbres y cultura griegas aún no habían penetrado decididamente en la forma de vida romana, y aunque su dominación sobre las colonias de la Magna Grecia daba lugar a contactos muy poderosos, la influencia de la manera de ser helénica no se había hecho dominante dentro de la perspectiva latina. Basta con pensar que más de un siglo después Cornelio Nepote advierte a sus lectores sobre las diferencias entre las costumbres de ambos pueblos y de la necesidad de juzgar las costumbres dentro del ambiente social en que se crean, aunque nos parezcan disímiles e incluso aberrantes en relación a las propias 5 .

Es por ello que Plauto introduce diferentes elementos de indudable carácter latino dentro de sus comedias, los que varían desde palabras jurídicas romanas para referirse a negocios griegos hasta las descripciones físicas de los lugares donde se ambientan las comedias.

El presente artículo se centrará en un esfuerzo de exploración de la realidad romana presente en las obras de Plauto, especialmente en lo relativo al sensual y oscuro mundo de las cortesanas.

\section{Las cortesanas durante el siglo II a.C.}

El universo de las cortesanas presenta mucho más interés para el estudioso de la sociedad romana de la República que el de las pocas mujeres virtuosas que aparecen en la comedia plautina.

Aunque tal mundo tiene un carácter originalmente griego, heredado de las hetairas que dieron color a la sociedad ateniense del siglo IV a.C.,

\footnotetext{
${ }^{4}$ Watson, Alan: The Law of Persons in the Later Roman Republic, 1984.

${ }^{5}$ Vidas, Praefatio, 1-8.
} 
puede entenderse que tenía mucho en común con la sociedad romana de la época de Plauto, pues de lo contrario las comedias que en ellas se centran serían incomprensibles para los romanos. Si bien son sociedades diferentes, podemos creer que coincidían lo suficiente como para entenderse en este plano $^{6}$.

La cortesana corresponde a un tipo especial de prostituta que florece a lo largo de la comedia plautina. Son mujeres jóvenes que reciben a sus amantes en su propia casa, a diferencia de las prostitutas vulgares que reciben en la calle ${ }^{7}$.

No cobran directamente una tarifa por mantener relaciones sexuales, sino que piden regalos y dinero en cantidad variable según la habilidad que tengan para expoliar a sus amantes.

Sus servicios sexuales son prestados en banquetes a los que invitan a sus amantes durante la noche.

Pueden ser tanto libres como esclavas; entre las primeras aparecen Filenia en Asinaria, ambas Báquides en Bacchides, Selenia y Gimnasia en Cistellaria, Erocia en Menaechmi y Fronesia en Truculentus; entre las segundas están Planesia en Curculio, Lemniselene en Persa, Adelfasia y Anterátile en Poenulus, Violeta en Pseudolus y, finalmente, Palestra y Ampelisca en Rudens.

Son estas mujeres el tipo básico que representa el amor en la comedia plautina. Los jóvenes e incluso los viejos pierden la cabeza por conquistar sus favores. Ellas tienen un margen de libertad amplio para elegir sus amantes y, generalmente, lo utilizan para elegir aquellos que mayores beneficios económicos les reporten.

\footnotetext{
${ }^{6}$ Sobre las semejanzas y diferencias entre ambas sociedades se ha escrito bastante. Seguramente los textos más importantes son Fraenkel, Eduard: Plautinisches im Plautus, 1922, y Costa, Emilio: Il Diritto Privato Romano nelle Commedie di Plauto, 1968. El punto en particular que expresamos aquí sobre la comunicabilidad de las experiencias en ambas comunidades lo trata singularmente bien, aunque tal vez de una manera excesivamente crítica, Paoli, Ugo Enrico: Comici Latini e Diritto Attico, 1962, pp. 40 y ss.

${ }^{7}$ Así, en Cistellaria, Gimnasia se niega a permanecer en plena calle, pues afirma ser eso cosa de prostitutas:

\{Gymn.\} Intro abeo, nam meretricem astare in via solam prostibuli sanest.

Trad: [Gymansia]: Mejor entro, ya que es de putas estar sola en la calle, no de cortesanas.

También en Pseudolus, el lenón Balión amenaza a sus cortesanas con hacerlas prostitutas callejeras (v.177):

nam nisi mihi penus annuos hodie convenit, cras populo prostituam vos.

Trad.: A menos que en mi casa haya hoy provisiones para un año, mañana mismo os convierto en putas callejeras.
} 
Existen dos tipos básicos de cortesanas que aparecen en las comedias. Unas son mujeres fatales que centran su atención descaradamente en el dinero de sus amantes. Capaces de todo, defienden su causa en base a la inconstancia de los amantes y la necesidad de lucrar con el sexo para vivir. Los tipos clásicos de esta clase de cortesana son las Báquides, Erocia y Fronesia; esta última incluso llega a suponer un parto a fin de extraer dinero de uno de sus amantes, el soldado Estratófanes.

El segundo tipo corresponde a la cortesana fiel, sinceramente enamorada de su amante y que le entrega sus favores en exclusiva. Conmovedor es el cariño que Selenia le presta a Alcesimarco, incluso cuando se entera que pretende casarse con una joven noble y rica. También resulta dulce la desesperación de Filocomasia por Pleusicles en el Miles Gloriosus al verse privada de su amor por haber sido raptada por el soldado Pirgopolinices.

\section{Reconocimiento y matrimonio}

En general las cortesanas son figuras queridas para Plauto, ya que ni aún a las más descaradas les llega a aplicar castigo alguno, sino que normalmente corona con el éxito sus esfuerzos. Las buenas y fieles normalmente son "premiadas" con el reconocimiento de sus verdaderos padres y el consecuente matrimonio con su amante.

El reconocimiento es una escena muy particular del gusto de la época. Se trata normalmente de hijas de buena familia que han sido abandonadas por sus padres o raptadas en su infancia. Viven siendo cortesanas, pero por algún motivo o han tenido a un solo amante, como Selenia en Cisterallia, o están a punto de iniciar su carrera como meretrices, pero mantienen todavía su virginidad, como Adelfasia y Anterátile en Poenulus. En ese momento, por una casualidad es descubierto su verdadero origen libre y ciudadano que las habilita para contraer matrimonio con su amante.

Es curioso que en la comedia plautina los hijos expósitos mantengan su condición de ingenuos ${ }^{8}$ y libres. Sabemos que en el Principado eran considerados esclavos ${ }^{9}$, por lo que suponemos que este tipo de escenas son de factura griega, aunque podría ser que durante la República su situa-

${ }^{8}$ Se entiende por ingenuo la persona que ha nacido libre, en contraposición a los libertos que nacen esclavos pero son liberados por sus amos.

${ }^{9}$ Detalles sobre la evolución en la condición de los expósitos se encuentran en Franciosi, Gennaro: Famiglia e Persone in Roma Antica, pp. 58 y ss., Volterra, Edorado: "L'Efficacia delle Costituzioni Imperiali Emanate per le Province e l'Istituto dell'Expositio", pp. 449 y ss. y Pugliese, Giovanni, "Note sull'Expositio in Diritto Romano", VI, pp. 629 y ss. 
ción fuese diferente. Sin embargo, no contamos con antecedentes suficientes para pronunciarnos en ningún sentido al respecto.

A propósito de los expósitos y el reconocimiento que los habilita a contraer matrimonio con los nobles jóvenes de la comedia, tiene interés plantearse el asunto de si los ingenuos y las libertas tenían connubio (matrimonio) entre sí en la época que tratamos ${ }^{10}$.

El punto es que en las comedias de Plauto, siempre la intención matrimonial se manifiesta luego del reconocimiento. Antes del mismo, el joven tiene usualmente la idea de hacer de la futura liberta su amante o concubina, pero sólo es después del reconocimiento cuando dichas intenciones se alteran y termina por pedirla en matrimonio. La pregunta más natural es plantearse si en la época existía una prohibición de dicho matrimonio, entre liberta e ingenuo, o no.

El debate sobre la cuestión es bastante antiguo y se extiende desde la época de Mommsen hasta nuestros días ${ }^{11}$.

Al respecto, Bonfante señala que existía una prohibición sancionada sólo por la religión (el fas), que perdió vigencia hacia el fin de la República, para ser restablecida como prohibición por Augusto sólo respecto a los hijos y nietos de senadores ${ }^{12}$ y Watson mantiene una opinión similar ${ }^{13}$. Por otra parte, Franciosi ${ }^{14}$ y Gómez Ruiz ${ }^{15}$ sostienen que antes de la época augustea se encontraba absolutamente prohibido tal matrimonio y que fue la legislación imperial la que vino a permitirlo, pero con la limitación de la clase senatorial.

${ }^{10}$ Como se sabe, el matrimonio en Roma exigía que tanto el marido como la mujer fuesen ciudadanos romanos y si alguno de ellos no lo fuese, al menos debía tener conubium. Naturalmente, dentro de esta óptica, los esclavos no podían contraer matrimonio pues no eran ciudadanos. Al efecto señala Ulpiano, en Reg., 5,5 “cum servis nullum est conubium" (con los esclavos no hay connubio).

${ }^{11}$ El punto se inicia con la opinión de Mommsen (Römisches Staatsrecht, 3, I, pp. 429 y ss.) que afirma que el matrimonio entre ingenuos y libertos se encontraba prohibido hasta la lex Iulia de maritandis ordinibus de Augusto. Esta posición se hizo completamente predominante en la literatura de la época (ad. ex. Girard, Paul: Manuel Élementaire de Droit Romain, pp. 125 y Meyer, Eduard: Der Römische Konkubinat, pp. 24 y ss.). A pesar del peso de sus partidarios, dicha teoría encontró opositores también desde antiguo y ya Karlowa (Römische Rechtsgeschichte, 2, 172) y Rossbach (Untersuchungen über die römische Ehe, pp. 456) atacan esta posición. Excelentes resúmenes del estado del debate se encuentran en Corbett, Roman Law of Marriage, pp. 30 y ss., como también en Watson, Alan: The Law of Persons in the Later Roman Republic, pp. 32 y ss.

${ }^{12}$ Bonfante, Pietro: Corso di Diritto Romano, Diritto di Famiglia, pp. 270 y ss.

${ }^{13}$ Watson, Alan: The Law of Persons in the Later Roman Republic, pp. 32 y ss.

${ }^{14}$ Franciosi, Gennaro: Famiglia e Persone in Roma Antica, pp. 157 y ss.

${ }^{15}$ Gómez Ruiz, Concepción: El Divorcio y las Leyes Agusteas, pp. 17 y ss. 
Los argumentos usados en este debate son diversos. El fundamental es el texto de Livio referente a los premios concedidos a Hispala Faecenia, una cortesana liberta que ayudó a descubrir la conjura de la Bacanales en el año 186 a.C., es decir, en la misma época que Plauto escribía:

Y así a Hispala Faecenia le fue dada la [capitis] deminutio, el derecho a casarse fuera de la gens [grupo clónico], de escoger tutor de igual manera que si su marido se lo hubiese concedido por testamento; asimismo, se permitió a ingenuo casar con ella y que no fuera para quién la desposara fraudulento o ignominioso $^{16}$. A.U.C. 39.19.5 (el destacado es mío).

La voz fraudi ignomiave (fraudulento o ignominioso), como bien señala Watson ${ }^{17}$, tiende a indicar una contravención a los mores (usos de los mayores), lo que implicaría la posible aplicación de una nota censoria en contra del contrayente si Hispala Faecenia no contase con el privilegio senatorial.

Aparentemente, con la caída de la autoridad del censor durante el siglo I a.C. después de la revolución conservadora de Sila, dicha prohibición habría dejado de estar en pleno vigor, pues en la época de Cicerón existían matrimonios entre libertas e ingenuos sin problemas jurídicos de ninguna especie, aunque manteniéndose como censurables ante la opinión pública, como parece indicarse en Pro Sestio (52. 110):

¿Por ventura existió alguna sedición en que no fuese aquel príncipe? ¿Hay acaso algún sedicioso que no sea amigo de aquél? ¿Existe algún tumulto del que no sea instigador? ¿Hay alguno a quien alguna vez haya recomendado algo bueno? ¿Algo buenamente recomendado? Al contrario, ¿no petulantísimamente es atacado quien es valiente y buen ciudadano? Éste, que según creo, no por causa del deseo, sino para aparecer como más popular, se casó con una liberta ${ }^{18}$. (El destacado es mío.)

16 "utique Faeceniae Hispalae datio, deminutio, gentis enuptio, tutoris optio item esset, quasi ei uir testamento dedisset; utique ei ingenuo nubere liceret, neu quid ei qui eam duxisset ob id fraudi ignominiaeue esset”.

${ }^{17}$ Watson, Alan: The Law of Persons in the Later Roman Republic, pp. 33.

18 "Ecquae seditio umquam fuit in qua non ille princeps? ecqui seditiosus cui ille non familiaris? ecquae turbulenta contio cuius ille non concitator? Cui bene dixit umquam bono? bene dixit? immo quem fortem et bonum civem non petulantissime est insectatus? qui, ut credo, non libidinis causa, sed ut plebicola videretur, libertinam duxit uxorem”. 
De esta manera se explica la aparente contradicción entre los diferentes textos que se refieren a la materia, en que Paulo ${ }^{19}$, citando las palabras de la ley agustea nos señala que ésta prohibía el matrimonio entre libertas e ingenuos de rango senatorial (antes permitido), mientras que Dión Casio ${ }^{20} \mathrm{y}$ Celso $^{21}$ nos indican exactamente lo contrario, que la ley estaría permitiendo todos los matrimonios entre libertas e ingenuos (antes prohibidos), salvo el de los pertenecientes al orden senatorial. En definitiva, la cuestión depende del enfoque que se dé al asunto. Antes de las leyes agusteas, existía una prohibición general en los mores de este tipo de matrimonios, pero al estar confinado su cumplimiento a la autoridad de los censores (la que decayó en el último siglo de la República), su incumplimiento quedó sin sanción, por lo que en la práctica estaba permitido. De esta manera, las leyes de Augusto vinieron a permitir el matrimonio entre ingenuos y libertas desde el punto de vista de los mores, pero a prohibirlo entre ingenuos senatoriales y libertas desde el punto de vista práctico. Así, Augusto restableció la coherencia del sistema siendo su normativa jurídicamente permisiva, pero prácticamente prohibitiva.

Cabe ahora preguntarse si la prohibición de los mores se extendía también a quienes se hubiesen dedicado a la prostitución, las artes teatrales o en general a todas las mujeres que se califica de famosae (mala reputación), como aparece en las leyes de Augusto.

En la comedia plautina, por regla general, sólo se habla de matrimonio después del reconocimiento. Un ejemplo claro es Curculio, donde Fédromo promete a Planesia darle su libertad para que sea su amante, pero un

${ }^{19}$ Digesto 23.2.44. 23.2.44.pr "Y también dice la ley Julia lo siguiente: que ningún senador, hijo de senador o biznieto de senador, a sabiendas y con dolo se comprometa o se case con una mujer liberta o cuya madre o padre ejerza o haya ejercido la profesión de exhibirse en público; ni la hija, nieta o biznieta de un senador, a sabiendas y con dolo se comprometa o case con un liberto o con hijo de padre o madre que haya ejercido aquella profesión.” Paulus libro primo ad legem Iuliam et Papiam. Lege Iulia ita cauetur: "Qui senator est quiue filius neposue ex filio proneposue ex filio nato cuius eorum est erit, ne quis eorum sponsam uxoremue sciens dolo malo habeto libertinam aut eam, quae ipsa cuiusue pater materue artem ludicram facit fecerit. neue senatoris filia neptisue ex filio proneptisue ex nepote filio nato nata libertino eiue, qui ipse cuiusue pater materue artem ludicram facit fecerit, sponsa nuptaue sciens dolo malo esto neue quis eorum dolo malo sciens sponsam uxoremue eam habeto".

${ }^{20}$ Historiae Romanae 54.16 y 56.7.

${ }^{21}$ Digesto 23.2.23. libro trigesimo digestorum. "Dispone la ley Papia que todos los libres de nacimiento, salvo los senadores y sus descendientes, pueden casarse con libertos." ("Lege Papia cauetur omnibus ingenuis praeter senatores eorumque liberos libertinam uxorem habere licere”.) 
poco más tarde, cuando se descubre que es ingenua de nacimiento y hermana del soldado Terapontígono, la pide en matrimonio (v.660 y ss.).

Aceptamos que esto puede ser consecuencia tanto de un prejuicio social como de un impedimento jurídico, pero la situación cambia cuando analizamos la misma cuestión en Cisterallia. Aquí la trama es sutilmente distinta. Selenia es una cortesana, quien, a pesar de haber tenido un único amante, pertenece a dicha clase. Es también una niña abandonada, pero ha sido criada por Melénide, otra cortesana, como si fuese su hija. Siendo Melénide una liberta, su hija es ingenua, por lo que Selenia sería una cortesana ingenua obscuro loco nata y famosa (de orígenes humildes y que se ha dedicado a la prostitución) por añadidura. El prejuicio social contra tal tipo de matrimonio era tan fuerte como aquél existente en contra del matrimonio con una liberta, y en ambos casos es necesario que se produzca el reconocimiento para que el matrimonio tenga lugar, pero sin embargo en dicha comedia ya se había comprometido Alcesimarco, su joven y noble amante, a casarse con ella antes de la escena del reconocimiento (v. 243):

\{Alc.\}Ella estaba dispuesta a pasar su vida conmigo en matrimonio ${ }^{22}$.

Incluso transcurre una amarga escena (cuya conservación en los papiros es muy lamentable) entre la supuesta madre de Selenia y Alcesimarco, en que ella le recuerda su deslealtad y el hecho de traicionar su palabra (v. 470 y ss.):

\{Alc\} Te lo juraré [laguna]

\{Mel\} Más yo no me valgo de tu juramento; se parece el juramento de los amantes a la turbación [laguna]

\{Alc\} No sé [laguna]

\{Mel\} Dices estupideces [laguna]

[laguna de difícil reconstrucción semántica]

\{Mel\} Tratas en vano de engañar a quien no lo permite. Igualmente, si yo aceptara tus palabras, los dioses nunca las aceptarán.

\{Alc\} Yo sin duda quiero casarme con ella.

\{Mel\} La desposarías sólo si te resultase cómodo [laguna]

[laguna]

$\{$ Mel $\}$ Te burlas porque tienes otra prometida, esa rica Lemnos.

Quédatela. Nosotras no somos de tu rango social y nuestros

22 “Quae esset aetatem exactura mecum in matrimonio”. 
bienes no son tan grandes como los tuyos, pero al menos no temo que me digan perjura. En cuanto a ti, si algo malo sucede, ya sabes por qué ${ }^{3}$.

Es decir, no obstante ser Selenia una cortesana, era posible para Alcesimarco contraer matrimonio con ella, aunque era socialmente reprobable, mientras que los demás amantes plautinos no podían plantearse el matrimonio sino después del reconocimiento. La diferencia parece encontrarse, en consecuencia, en la calidad de ingenua que mantiene Selenia a pesar de su condición de cortesana.

En definitiva, creemos que en la época de Plauto había una prohibición de matrimonio que pesaba sobre las uniones entre ingenuos y libertas, pero que no existía una limitación para los matrimonios entre ingenuos e ingenuas quarum pater materve artem ludicram fecerit (cuyo padre o madre se dedicaran a exhibirse públicamente) ${ }^{24}$, la que sería una innovación de

${ }^{23}$ La escena completa es como sigue:

" $\{$ Alc. $\}$ Dabo ius iurandum.*

\{Mel.\} At ego nunc <ab> illo mihi <caveo > iure iurando tuo; similest ius iurandum amantum quasi ius confusicium.

\{Alc. Nescia * *

$\{$ (Mel.) $\}$ nugas agis. $* * *$

\{Alc.\} Supplicium dabo * quo modo ego **

$\{($ Mel. $)\}$ quia es nactus novam, quae * quaedam quasi tu nescias. ${ }^{*}$

\{Alc.\} Di deaeque illam perdant pariter. * umquam, si hoc fallo.

\{Mel.\} Nil moror $*$ falsum fallis, eo te $*$ ignorat fides. postremo, si mihi dedisses verba, deis numquam dares.

\{Alc.\} Quin equidem illam ducam uxorem.

\{Mel.\} Ducas, si * nunc hoc si tibi commodumst, quae *

\{Alc. Instruxi illi aurum atque vestem.

$\{($ Mel. $)\} *$ siquidem amabas, * illi instrui. sed sino. iam hoc mihi responde quod $<$ ego > te rogavero: instruxisti * tibi ita ut voluisti *

$\{$ (Alc.)\} quod volo.

\{Mel.\} Eo facetu’s quia tibi aliast sponsa locuples Lemnia. habeas. neque nos factione tanta quanta tu sumus neque opes nostrae tam sunt validae quam tuae; verum tamen hau metuo ne ius iurandum nostrum quisquam culpitet: tu iam, si quid tibi dolebit, scies qua doleat gratia.

\{Alc. Di me perdant-

\{Mel.\} Quodcumque optes, tibi velim contingere.

\{Alc.\} Si illam uxorem duxero umquam, mihi quam despondit pater.

\{Mel.\} Et me, si umquam tibi uxorem filiam dedero meam.

\{Alc.\} Patierin me periurare?

\{Mel.\} Pol te aliquanto facilius, quam me meamque rem perire et ludificari filiam. alibi quaere ubi iuri iurando tuo satis sit subsidi: hic apud nos iam, Alcesimarche, confregisti tesseram”.

${ }^{24}$ Digesto 23.2.23; Digesto 23.2.27; Digesto 23.2.34.3; Digesto 23.2.42.1;

Digesto 23.2.44 
la Lex Iulia de maritandis ordinibus, pues de lo contrario, no tendría sentido la propuesta de matrimonio de Alcesimarco a Selenia, ni menos aun los reproches que Melénide le dirige.

\section{El problema del concubinato}

Respecto al establecimiento por Augusto de limitaciones a la capacidad matrimonial, se suele señalar que ésta sería la causa del surgimiento del concubinato durante el principado como institución social, que derivará en jurídica en la época justinianea ${ }^{25}$. El punto estaría en que, puesto que determinadas personas no podrían contraer matrimonio entre sí, comenzaron a convivir de manera estable sin por ello contraer matrimonio, dando lugar a la institución llamada concubinato que pasará a estar regulada jurídicamente en etapa postclásica y por influencia cristiana ${ }^{26}$. En efecto, para los romanos el concubinato era una suerte de espejo del matrimonio, pues era una unión de carácter estable en la cual, por faltar capacidad para contraer matrimonio (connubio) no podía hablarse de matrimonio. La concubina era, a diferencia de una simple amante, una pareja permanente, similar a lo que modernamente se ha dado en denominar "uniones de hecho".

${ }^{25} \mathrm{Al}$ respecto véase Thomas, J.: “Concubinatus in Roman Marriage”, pp. 230 y ss.

${ }^{26}$ Como es bien sabido, el matrimonio no era para los romanos un contrato sino meramente una situación de hecho. Éste, a grandes rasgos, tenía lugar toda vez que una pareja de ciudadanos convivía y se trataban mutuamente como marido y mujer (affectio maritalis). Por esto es que, en general, la inmensa mayoría de las parejas que hoy llamaríamos "de hecho" eran matrimonios propiamente tales para la mentalidad romana. Sobre el rol de la affectio maritalis y de la convivencia se ha debatido extensísimamente. La literatura fundamental sobre el tema es la siguiente: Bonfante, Pietro: Corso di Diritto Romano, Diritto di Famiglia; Castello, Carlo: Studi sul Diritto Familiare e Gentilizio Romano, 1972; Corbett, Percy Ellwood: The Roman Law of Marriage; Gaudemet, Jean: “Originalité et Destin du Marriage Romain”, pp. 55 y ss. y del mismo autor "Justum Matrimonium”, v. III, pp. 103 y ss.; Lauria, Mario: MatrimonioDote in Diritto Romano; Orestano, Riccardo: La Struttura Giuridica del Matrimonio Romano; Robleda, Olis: "Matrimonio Inexistente o Nulo en Derecho Romano”, 1973, v. III, pp. 1131 y ss.; Solazzi, Siro: "Consortium Omnis Vitae”, v. III, pp. 313 y ss. y del mismo autor "Sui Divieti Matrimoniali delle Leggi Augutee”, v. IV, pp. 81 y ss.; Treggiari, Susan: Roman Marriage, 1991; Volterra, Edoardo: “Iniustum Matrimonium”, 1972.

El problema del concubinato surge cuando dos personas que reúnen estos elementos no pueden, sin embargo, estar casadas, como es el caso de la liberta y el ingenuo senatorial. Es desde esta óptica, puesto que aquí no puede haber matrimonio, que surge el concubinato, institución eminentemente social mas no jurídica. 
Sin embargo, si aceptamos que una prohibición similar a la augustea se encontraba en los mores durante el siglo II a.C., es posible que el concubinato haya surgido como forma social antes de las prohibiciones de $\mathrm{Au}-$ gusto, decayendo durante el último siglo de la República, para resurgir en el principado producto de la Lex Iulia de maritandis ordinibus. Al respecto es muy interesante el análisis de Watson ${ }^{27}$ sobre los usos de la palabra concubina en Plauto.

Lo común es estimar que amica y concubina son sinónimos durante el siglo II a.C., pero, de conformidad al autor, existen 23 casos en que la palabra concubina o concubinato son usados a lo largo de la comedia plautina, siendo amica la voz absolutamente preponderante para referirse a las amantes.

El caso de mayor interés es el de Filocomasia, en Miles Gloriosus. En dicha comedia, la cortesana Filocomasia fue raptada por Pirgopolinices, soldado fanfarrón y engreído que será sistemáticamente burlado durante toda la comedia. Filocomasia está enamorada de Pleusicles, con quien mantiene relaciones a espaldas de Pirgopolinices, a pesar de vivir con él, supuestamente, de manera monogámica. La cuestión es que en todas las ocasiones en que se habla de la relación de Filocomasia con Pirgopolinices se utiliza la voz concubina o concubinato, mientras que sólo se la llama amica de Pleusicles.

¿Es diferente la relación que mantiene con Pirgopolinices a aquella que tiene con Pleusicles para que se la denomine por dos nombres diferentes durante toda la obra?

Sabemos que, con la salvedad de Filocomasia, ninguna de las cortesanas que aparecen en la comedia plautina vive con su amante. Algunas de ellas son monógamas, como Selenia, pero sin embargo sólo se las denomina amicae, por lo que la mantenencia de relaciones sexuales en exclusiva no puede ser la diferencia esencial.

Aparentemente, la diferencia de denominación entre Filocomasia respecto a Pirgopolinices y Pleusicles responde al hecho que vive con uno de ellos y es, por tanto, más propiamente su concubina que su amante.

En cuanto a la posibilidad que dicha diferencia sea de origen heleno y que Plauto se limite sólo a traducir las voces ya presentes en el original, debemos agregar que nos parece irrelevante, pues como señala Watson: "No tenemos qué decidir acerca de esta cuestión, puesto que, si Plauto en su elección de palabras mantiene una distinción del griego, la diferencia en el uso de las voces 'concubina' y 'amica’ muestra, a su vez, que la posición de las concubinas es diferente a la de otras amantes" ${ }^{28}$.

${ }^{27}$ Watson, Alan: The Law of Persons in the Later Roman Republic, 1 y ss.

${ }^{28}$ Watson, Alan: The Law of Persons in the Later Roman Republic, 1984. 
Otro detalle curioso es que antes de iniciar relaciones con una nueva amante, Pirgopolinices señala de una manera muy sugestiva que debe librarse de Filocomasia, pues no puede recibir a una nueva amante en casa mientras tenga ahí a su concubina (v.1095):

\{Pyrg.\} Palestrio, ¿qué me recomiendas que haga ahora respecto a mi concubina? Porque sin haberme desecho de ella, no puedo de ninguna manera recibir a aquella [su nueva amante] en $\operatorname{casa}^{29}$.

¿Significa esto que la relación con una concubina sea monógama? ¿No se pueden mantener dos concubinas al mismo tiempo? Aparentemente sólo se podría mantener una sola concubina, pero es un tanto arriesgado afirmarlo tajantemente.

En definitiva, nos inclinamos a concluir que existía en tiempos de Plauto una diferencia social entre las concubinas y las demás amantes que se podían tener, siendo esencialmente que una concubina vivía con un amante y que, posiblemente, sólo era aceptable socialmente mantener una concubina. Estos rasgos acercarían la noción plautina de concubina al concepto clásico y postclásico de la misma, siendo lícito afirmar que la concepción social de la concubina es muy anterior a la época del principado y que se habría encontrado diferenciada y definida en el imaginario popular mucho antes que los juristas se hiciesen cargo de ella.

Finalmente, resulta interesante preguntarse sobre los métodos anticonceptivos con que en esta época contaban las cortesanas.

Evidentemente, al utilizar su sexualidad con fines comerciales debían disponer de alguna fórmula que les permitiese trabajar sin encontrarse permanentemente embarazadas. Aparentemente, existían varios métodos anticonceptivos en uso en aquella época ${ }^{30}$, aunque posiblemente de una menor efectividad que los modernos.

En caso de fallar, la alternativa obvia para una cortesana, aunque altamente peligrosa por los escasos medios sanitarios, era el aborto. De hecho, en Truculentus, Fronesia amenaza a su amante con abortar a su supuesto hijo a fin de que éste le haga mayores regalos ${ }^{31}$. Sabemos que el aborto era uno de los más serios delitos que una materfamilias podía come-

29 “ $\{$ Pyrg. $\}$ Quid nunc mi es auctor ut faciam, Palaestrio, de concubina? nam nullo pacto potest prius haec in aedis recipi quam illam amiserim.”

${ }^{30} \mathrm{Al}$ respecto, un muy interesante estudio se encuentra en Treggiari, Susan: Roman Marriage, pp. 405 y ss., con abundante bibliografía.

${ }^{31}$ Truculentus, v. 200 y ss. 
ter, pero parece ser que respecto a las cortesanas el asunto no revestía mayor importancia.

Otra alternativa menos riesgosa desde el punto de vista de la salud de la mujer era simplemente tener el hijo y decidir abandonarlo o criarlo luego del parto. De aquí vendría una larga línea de niños expósitos que sabemos existieron en Roma durante toda la época republicana e imperial.

\section{ÍNDICE DE FUENTES 32}

\section{Fuentes literarias:}

Cicerón: Pro Sestio: 52, 110. Traducción de J. J. Baños Baños. Madrid: Gredos, 1994.

Cornelio Nepote: Vidas, Prefacio, 1-8. Traducción de Manuel Segura Moreno. Madrid: Gredos, 1985.

Dión Casio: Historia Romana, 54,16; 56,7. Traducción de Domingo Plácido Suárez. Madrid: Gredos, 2004.

Plauto, Comedias (Cisterallia, 117; 243; 470; Curculio, 660; Miles Gloriosus, 1095; Truculentus, 200). Traducción de José Román Bravo. Madrid: Cátedra, 1998.

Tito Livio: Historia de Roma desde la Fundación de la Ciudad, 39, 19, 5. Traducción de José Antonio del Villar. Madrid: Gredos, 1990.

\section{Fuentes jurídicas:}

Justiniano: Digesto, 23,2,23; 23,2,27; 23,2,34; 23,2,42; 23,2,44. Traducción de Álvaro D’Ors. Pamplona: Aranzadi, 1972.

Ulpiano: Reglas, 5,5. Traducción de Nina Ponsa de la Vega. Buenos Aires: Ed. Lerner, 1970.

\section{BIBLIOGRAFÍA CITADA}

Bekker, Ernst Inmanuel: Die römischer Komier als Rechtszeugen. En ZSS, N 13/14 pp. 53 y ss.

Bonfante, Pietro: Corso di Diritto Romano, Diritto di Famiglia. Milano, Dott.: A. Giuffrè Editore, 1963.

Castello, Carlo: Studi sul Diritto Familiare e Gentilizio Romano. Roma: “L’Erma” di Bretschneider, 1972.

Corbett, Percy Ellwood: Roman Law of Marriage. Leipzig: Scientia Verlag Aalen, 1979.

${ }^{32} \mathrm{~A}$ fin de facilitar al lector la lectura de las obras citadas, se indica la última traducción disponible en el mercado editorial de dichas obras al idioma español. 
Costa, Emilio: Il Diritto Privato Romano nelle Commedie di Plauto. Roma: L’Erma di Bretschneider, 1968.

Fraenkel, Eduard: Plautinisches im Plautus. Berlin: Weidmann, 1922

Franciosi, Gennaro: Famiglia e Persone in Roma Antica. Torino: G. Giappichelli Editore, 1992.

Gaudemet, Jean: “Originalité et Destin du Marriage Romain”. En Ėtudes de Droit Romain, Vol. III. Napoli: Jovene Editore, 1979.

“Justum Matrimonium”. En Ėtudes de Droit Romain, Vol. III. Napoli: Jovene Editore, 1979.

Girard, Paul: Manuel Élementaire de Droit Romain. Paris: Librarie Arthur Rousseau, 1918.

Gómez Ruiz, Concepción: El Divorcio y las Leyes Agusteas. Sevilla: Publicaciones Universidad de Sevilla, 1987.

Guarino, Antonio: “Minima de Mulieribus”. En Pagine di Diritto Romano, Vol. III. Napoli: Dott. Eugenio Jovene, 1993.

Karlowa, Otto: Römische Rechtsgeschichte. Leipzig: Veit \& comp., 1885.

Lauria, Mario: Matrimonio-Dote in Diritto Romano. Napoli: L’arte tipográfica, 1952.

Meyer, Eduard: Der römische Konkubinat. Leipzig: Neudr. d. Ausg., 1895.

Mommsen, Teodoro: Römisches Staatsrecht. Leipzig: Hirzel, 1877.

Orestano, Riccardo: La Struttura Giuridica del Matrimonio Romano. Milano: Dott. A. Giuffrè Editore, 1951.

Paoli, Ugo Enrico: Comici Latini e Diritto Attico. Milano: Dott. A. Giuffrè Editore, 1962.

Pugliese, Giovanni: “Note sull’Expositio in Diritto Romano”. En St. Sanfilippo. Milano: Dott. A. Giuffrè Editore, VI, 1985.

Robleda, Olis: "Matrimonio Inexistente o Nulo en Derecho Romano". En Studi in onore di Guido Donatuti. Vol. III. Milano: Istituto, Editoriale Cisalpino, 1973.

Rossbach, August: Untersuchungen über die römische Ehe. Stuttgart: Märken, 1853.

Solazzi, Siro: “Consortium Omnis Vitae”. En Scritti di Diritto Romano. Vol. III. Napoli: Dott. Eugenio Jovene.

“Sui Divieti Matrimoniali delle Leggi Augutee”. En Scritti di Diritto Romano. Vol. IV. Napoli: Dott. Eugenio Jovene, 1960.

Thomas, J.: “Concubinatus in Roman Marriage”. En Huldigningsbundel Paul Van Warmelo. Pretoria: Universeit Van Suid Afrika, 1984.

Treggiari, Susan: Roman Marriage. Oxford: Clarendon Press, 1991.

Volterra, Edorado: "L’Efficacia delle Costituzioni Imperiali Emanate per le Province e l'Istituto dell’Expositio”. En St. Besta, I. Milano: Dott. A. Giuffrè Editore, 1937.

“Iniustum Matrimonium”. En Studi in Onore di Gaetano Scherillo. Vol. II, Milano: Istituto Editoriale Cisalpino, 1972.

Watson, Alan: The Law of Persons in the Later Roman Republic. Leipzig: Scientia Verlag Aalen, 1984. 